\title{
Plastik Enjeksiyon Kalıplama Yöntemi ile Sac Metallerin Şekillendirilebilirliğinin İncelenmesi
}

\author{
Murat ŞEN $^{1}$, Mihrigül Ekşi ALTAN ${ }^{2}$ \\ ${ }^{1}$ Marmara Üniversitesi, Teknoloji Fakültesi, Makine Mühendisliği Bölümü, İstanbul, Türkiye \\ ${ }^{2}$ Yıldız Teknik Üniversitesi, Makine Fakültesi, Makine Mühendisliği Bölümü, İstanbul, Türkiye
}

\section{ÖZET}

Günümüzde otomotiv, havacılık ve uzay endüstrisinde karmaşık geometriye sahip ve dar toleranslı parçaların kullanımı giderek artmıştır. Bunun yanı sıra enerji tüketimi imalat aşamasında proses seçimini etkileyen en önemli parametrelerden biri olmuştur. Bu çalışmada, endüstrinin talebini karşılayabilmek ve en az enerji tüketimiyle gerçekleştirebilmek amaciyla sac metal şekillendirme alanında oldukça sık kullanılan sıvı basıncı ile şekillendirme yöntemi incelenmiştir. Deneysel çalışmalar Al-1050.O malzemesi kullanılarak gerçekleştirilmiştir. Geleneksel sıvı basıncı ile şekillendirme yönteminde kullanılan yă̆ yerine plastik enjeksiyon makinesi yardımıyla ergitilen polimer malzeme kullanılmıştır. İstenilen formda ve tolerans aralığında maksimum şekillendirilebilirliğin sağlanabilmesi için ergiyik polimer sıcaklığı, enjeksiyon basıncı ve enjeksiyon hızı gibi proses parametreleri dikkate alınarak deneysel çalışmalar yapılmıştır. Taguchi metodu ile optimum proses parametreleri belirlenmiştir. ANOVA metodu ile de parametrelerin, şekillendirilen sacın incelmesi üzerine etkinlikleri irdelenmiştir. Şekillendirme üzerinde enjeksiyon basıncı ve ergiyik sıcaklığının sırasıyla en etkili parametreler olduğu görülmüştür. Ayrıca şekillendirme öncesi malzemeye uygulanan ön ısıtma işleminin uygulanması ile yöntemin uygulanabilirliğinin ve performansının arttığ 1 gözlemlenmiştir.

Anahtar kelimeler: Plastik enjeksiyon kalıplama, Sac metal şekillendirme, İncelme oranı, Taguchi metodu.

\section{Investigations of Formability of Sheet Metals by Plastic Injection Molding Method}

\begin{abstract}
In recent years, the usage of parts which have complex geometry and low tolerance have been gradually increased in aviation, aerospace and automotive industries. Moreover, energy consumption has became one of the most important parameter in effecting of process selection during the manufacturing. In this study, hydroforming process which has widely used in sheet metal forming was investigated to compensate the demands of industry and enable to product with minimum energy consumption. Experimental work was carried out using Al1050.O material. In that process, a polymer material that melted by using a injection machine was used instead of oil that was performed in conventional hydroforming process. Experimental studies were conducted taking account of the temperature of polymer, injection pressure and injection velocity to provide maximum formability in demanded form and range of tolerance. Also, Taguchi method was used to determine optimum process parameters. The ANOVA method was used to examine the effectiveness of the parameters on thinning of shaped sheet metal. Injection pressure and temperature of polymer were found to be the most effective parameters, respectively. Furthermore, it was observed that the applicability and performance of method has increased with the application of the pre-heating process on parts before forming.
\end{abstract}

Keywords: Polymer injection molding, Sheet metal forming, Thinning ratio, Taguchi method. 


\section{GİRIŞ̧}

Plastik enjeksiyon kalıplama yöntemi ile şekillendirme günümüzde sac malzemelerin imalatında kullanılan yeni bir yöntemdir (Şekil 1). Bu yöntem otomotiv, havacılık ve uzay endüstrisinde hafif, hassas, estetik ve fonksiyonel parçaların imalatında geleneksel derin çekme metoduna alternatif olarak günümüzde tercih edilmektedir. Yöntemin üstün yanları şekillendirme sonrası iyi yüzey kalitesine ve düşük artık gerilmelere sahip parçaların elde edilmesi ve maliyeti daha düşük, dayanıklı, rijit parçaların imalatının yapılabilmesidir. Geleneksel derin çekme yönteminden zayıf yanları ise şekillendirme süresinin uzun olması ve yüksek basınç gereksinimidir [1].

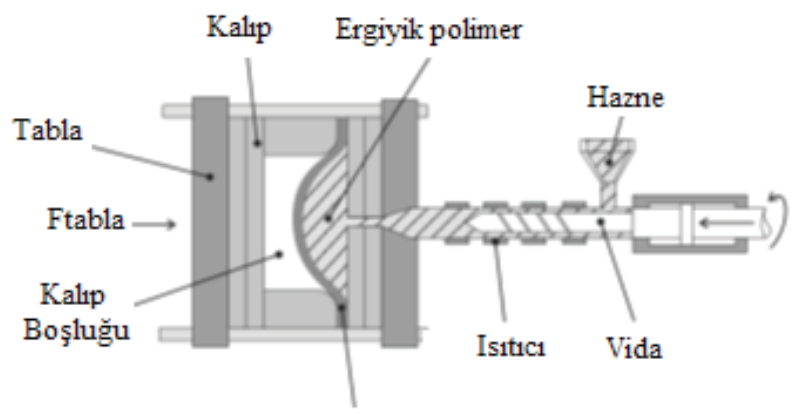

Sac metal

Şekil 1. Plastik enjeksiyon kalıplama yöntemi ile sac şekillendirme

Plastik enjeksiyonla şekillendirme yönteminde yüksek basınçlı akışkan olarak enjeksiyon makinesinde ergitilen polimer malzeme kullanılmaktadır. Plastik enjeksiyon makinesinde ergitilen polimer malzeme vida yardımıyla yüksek basınç kazanarak kalıba gönderilmektedir. Yüksek basınçlı polimer sac malzemenin ön yüzeyine temas ederek kalıp boşluğunun formunu almasını sağlamaktadır [2].

Plastik enjeksiyon makinesi kullanılarak yüksek basınçlı ergiyik polimerin enjeksiyonuyla sac metalin şekillendirmesinde, malzemenin son şeklini almasında birçok parametre etkilidir. Yöntemin üstün yanlarından biri de bu parametrelerin enjeksiyon makinesi üzerinden kolaylıkla kontrol altına alınabilmesidir. Şekillendirme üzerinde en çok etkisi olan basınç ve sıcaklık gibi parametreler makine üzerinden kontrol edilerek parçanın istenilen formda ve tolerans aralığında imal edilmesi sağlanabilmektedir. Genel olarak sac malzemelerin şekillendirilmesi sonucu parçadaki incelme miktarının tolerans değerleri arasında olması ve formunun tam olarak elde edilmesi aranılan isteklerin başında gelmektedir. $\mathrm{Bu}$ amaçla basınç, sıcaklık ve enjeksiyon hızı gibi parametrelerin optimum olarak elde edilmesi gerekmektedir. Buna yönelik olarak literatürde birçok çalışma yer almaktadır. Koç ve arkadaşları, plastik enjeksiyon kalıplama ile sac malzemelerin şekillendirilebilirliğini farklı proses parametreleri kullanarak incelemişlerdir. Proses parametreleri olarak sıcaklık, basınç ve pot kuvvetini ele alarak, bu parametrelerin proses sonu parça formuna, incelmesine ve boşluk doldurma oranına etkilerini değerlendirmişlerdir [3]. Lucchetta ve Baesso ise tek operasyonla metal ve polimerden oluşan makro-kompozit parçaların imalatını plastik enjeksiyon yöntemini kullanarak gerçekleştirmişlerdir. Çalışmalarında farklı enjeksiyon parametrelerinin sac metalin şekillendirilebilirliğine etkilerini deneysel olarak incelemişlerdir. Sonuç olarak şekillendirilebilirlik üzerine en etkili parametrelerin, polimerin ergime sicaklığ 1 ve makinenin kapama kuvveti olduğu sonucuna ulaşmışlardır [4]. Bu konuda bir başka çalışmada Bariani ve diğerleri, sonlu elemanlar yöntemini kullanarak metal-polimer kompozit parçalara yönelik fiziksel bir model oluşturmuşlardır. Böylece proses esnasında metal ve polimer malzemeleri arasındaki termal ve mekanik etkileşim görülerek, prosesi optimum koşullarda kontrol edebilmek ve en doğru tasarımı gerçekleştirebilmek mümkün hale gelmiştir. Çalışmalarını simülasyonlara ek olarak deneysel olarak ta gerçekleştirerek optimum modele ulaşmayı amaçlamışlardır [5]. Behrens ve arkadaşları, benzer olarak plastik enjeksiyonuyla şekillendirme yöntemine dayalı bir çalışma yapmışlardır. Bu çalışmada sac metal parçanın malzeme davranışı, sıcaklığa bağlı elasto-plastik malzeme modeli kullanılarak sonlu elemanlar metoduyla oluşturulmuştur. Nümerik çalışmalara ilaveten deneysel çalışmalar da gerçekleştirmişlerdir. Nümerik olarak elde edilen sonuçların deneysel çalışmalarla elde edilen sonuçlara yakın değerler verdiği sonucuna ulaşmışlardır [6]. Plastik enjeksiyonla sac şekillendirme prosesine ait bir başka çalışma da Michaeli ve Maesin tarafından gerçekleştirmişlerdir. Çalışmalarında alüminyum ve paslanmaz çelik metal parçalarının enjeksiyon yöntemiyle şekillendirilmesini esas almışlardır. Enjeksiyon proses parametrelerinin şekillendirmeye etkisini incelemişlerdir. Parametre olarak sıkıştırma basıncını, hızı ve polimerin ergime sıcaklığını dikkate alarak çeşitli deneysel çalışmalar gerçekleştirmişlerdir. Buna ek olarak sonlu elemanlar yöntemine dayalı simülasyonlarla deneysel verileri karşılaştırmışlardır [7]. Chen ve diğerleri, yeni bir yaklaşım olan metal-polimer makro kompozit parçaların enjeksiyon yöntemiyle imalatında farklı proses basınçları altındaki şekillendirilebilirliklerini, şekillendirilen parçaların farklı bölgelerindeki gerinim ve kalınlık dağılımlarını sonlu elemanlar yöntemiyle ve deneysel çalışmalarla incelemişlerdir [8]. Altan ve diğerleri, plastik enjeksiyon yöntemini kullanarak titreşim sönümleme amacıyla metal-polimer makro kompozit yapıların imalatını gerçekleştirmişlerdir. Çalışmalarında matris malzemesi olarak 1000 serisi alüminyum plakalar (Al-1100) ve takviye malzemesi olarak üç farklı polimer malzeme (PP, TPE ve 
$\mathrm{TiO}_{2}$ ilaveli PP) kullanmışlardır. Kompozit yapıların eğilme dayanımlarını ölçmek için üç noktadan bükme testi uygulamışlardır. Sonlu elemanlar yöntemine dayalı ANSYS yazılımını da kullanarak bükme sonuçlarını karşılaştırmışlardır. Çalışma sonucunda TPE kullanılarak oluşturulan makro kompozit yapının en yüksek sönümleme oranına sahip olduğu görülmüştür [9]. Karaağaç ve Özdemir ise sıvı basıncı ile şekillendirme yöntemiyle geleneksel derin çekme yöntemini şekillendirilebilirlik, kalınlık değişimi ve üç farklı polimer malzeme maliyet açısından karşılaştırmışlardır. Sıvı basıncı ile şekillendirme yönteminin dar toleranslı ve hassas parça imalatına, geleneksel derin çekme yöntemine göre daha uygun olduğuna ancak yüksek sıvı basınçlarının kullanılmasından dolayı ilk yatırım maliyetlerinin daha yüksek olduğu sonucuna gerçekleştirdikleri deneysel ve sonlu elemanlar çalışmalarıyla ulaşmışlardır [10]. Landgrebe ve diğerleri, plastik enjeksiyonla sac metal şekillendirme yönteminin enerji verimliliği üzerine bir çalışma yapmışlardır. $\mathrm{Bu}$ yeni yöntemin işlem sayısını düşürmesinden ve sadece tek taraflı kalıp elemanına ihtiyaç duymasından dolayı geleneksel yönteme göre $20 \%$ daha az enerji gereksinimine ihtiyaç duyduğu sonucuna ulaşmışlardır [11].

Plastik enjeksiyonla sac metal şekillendirme, yeni bir yöntem olmasından dolayı geleneksel derin çekme yöntemine göre işlem bilgisi açısından daha kısıtlıdır. Ayrıca proses parametrelerinin sonuca etkilerinin tam olarak bilinmemesi açısından dezavantaja sahiptir. Konu hakkında literatürde birçok çalışma bulunmasına rağmen farklı proses parametrelerinin şekillendirme üzerine ve parçalarda meydana gelen kalınlık ve iç yapı değişimlerine ait bir çalışma bulunmamaktadır. Bu amaçla, yapılan bu çalışmada enjeksiyon basıncı, ergiyik sıcaklığı ve enjeksiyon hızı gibi proses parametreleri dikkate alınarak çeşitli deneysel çalışmalar gerçekleştirilmiştir. Şekillendirme sonrası parçaların enine ve boyuna kalınlık değişimleri ölçülerek Taguchi ve ANOVA metotları ile optimum proses parametreleri elde edilmiştir. Ek olarak ön 1sıtma işlemi gerçekleştirilerek sacların şekillendirilebilirliğinin iyileştirilmesi sağlanmıştır.

\section{MATERYAL VE YÖNTEM}

\subsection{Malzeme}

Deneysel çalışmalarda otomotiv endüstrisinde yaygın olarak kullanılan Al-1050.O malzemesi seçilmiştir. Malzemeye ait kimyasal analiz sonuçları Tablo 1' de verilmiştir.

Tablo 1. Al-1050.O kimyasal analiz sonuçları (\%Hacim)

\begin{tabular}{cccccccc}
\hline $\mathrm{Al}$ & $\mathrm{Cu}$ & $\mathrm{Fe}$ & $\mathrm{Mg}$ & $\mathrm{Mn}$ & $\mathrm{Si}$ & $\mathrm{Ti}$ & $\mathrm{Zn}$ \\
\hline 99.5 & 0.05 & 0.4 & 0.05 & 0.05 & 0.25 & 0.03 & 0.07 \\
\hline
\end{tabular}

Malzemenin şekillendirilebilirliği üzerinde etkili olan mekanik özellikleri Tablo 2'de verilmiştir. Malzemenin kalıcı şekil değiştirebilmesi için akma sınırına ulaşması gerekmektedir. Akma mukavemetinin yüksek olması o malzemenin şekillendirilmesinin zor olduğunu göstermektedir. Tablo 2 incelendiğinde Al-1050.O malzemesinin akma mukavemetinin düşük olması sebebiyle kolay şekillendirilebilir olduğu görülmektedir.

Tablo 2. Al-1050.O mekanik özellikleri

\begin{tabular}{cccc}
\hline $\begin{array}{c}\text { Akma Mukavemeti } \\
(\mathrm{MPa}) \text { min-max }\end{array}$ & $\begin{array}{c}\text { Çekme Mukavemeti } \\
(\mathrm{MPa}) \text { min-max }\end{array}$ & $\begin{array}{c}\text { Uzama } \\
(\% 50)\end{array}$ & $\begin{array}{c}\text { Sertlik } \\
(\text { Brinell) }\end{array}$ \\
\hline $20-35$ & $65-80$ & 38 & $20-21$ \\
\hline
\end{tabular}

Deneysel çalışmalar $1.5 \mathrm{~mm}$ kalınlığındaki sac plakalar kullanılarak gerçekleştirilmiştir. Plakaların boyutları $76 \mathrm{~mm}$ x 116 mm' dir.

Deneysel çalışmalarımızda şekillendirme işlemini gerçekleştiren polimer malzemesi olarak polistiren tercih edilmiştir. Polistirene ait özellikler Tablo 3' te verilmiştir. Polistiren, monomer haldeki stirenden polimerizasyon ile üretilen bir termoplastiktir. Plastik endüstrisinde PS olarak bilinmektedir. Oda sıcaklığında katı halde bulunmaktadır, fakat enjeksiyon prosesi esnasinda yüksek sicaklıklarda ergiyik hale gelmektedir. Yoğunluğu ise 1,03-1,06 g/ml aralığında değişmektedir.

Polimer malzemesi olarak polistirenin tercih edilmesinde birçok parametre etkilidir. Bunların başında polistirenin düşük ergime noktasına sahip olması gelmektedir. Malzemenin ergime sıcaklı̆g $1210-250{ }^{\circ} \mathrm{C}$ aralığındadır. Polistirenin amorf bir yapıya sahip olmasından ötürü, işlem esnasında kendini çekmesi kısmi kristalin olan polimerlere göre daha düşüktür. $\mathrm{Bu}$ da sac metalin şekillendirilmesini daha etkili kılmaktadır. Ayrıca polistiren enjeksiyon yönteminde çok yaygın olarak kullanılan, kolaylıkla ulaşılabilen ve çok pahalı olmayan bir plastik türüdür.

Tablo 3. Polistiren yoğunluk ve ergime sıcaklığ1

\begin{tabular}{cc}
\hline Yoğunluk $(\mathrm{g} / \mathrm{ml})$ & Ergime sicaklı̆̆ $\left.1{ }^{\circ} \mathrm{C}\right)$ \\
\hline $1,03-1,06$ & $210-250$ \\
\hline
\end{tabular}

\subsection{Metot}

Plastik enjeksiyonla sac şekillendirmede tek taraflı kalıp kullanıldığı için kalıp maliyeti, işçiliği ve bakımı açısından üreticiye avantaj sunmaktadır. Geleneksel derin çekme yönteminde alt ve üst kalıp gereksiniminin olması tercihi plastik enjeksiyonla şekillendirme yöntemine kaydırmaktadır. 
Deneysel çalışmalarda kullanılan kalıbın katı modeli ve boyutları Şekil 2 ve 3' te verilmiştir. Parçanın hassas bir şekilde imal edilebilmesi için kalıp boşluğunun oldukça iyi işlenmesi ve yüzeyinin çok iyi parlatılması gerekmektedir.

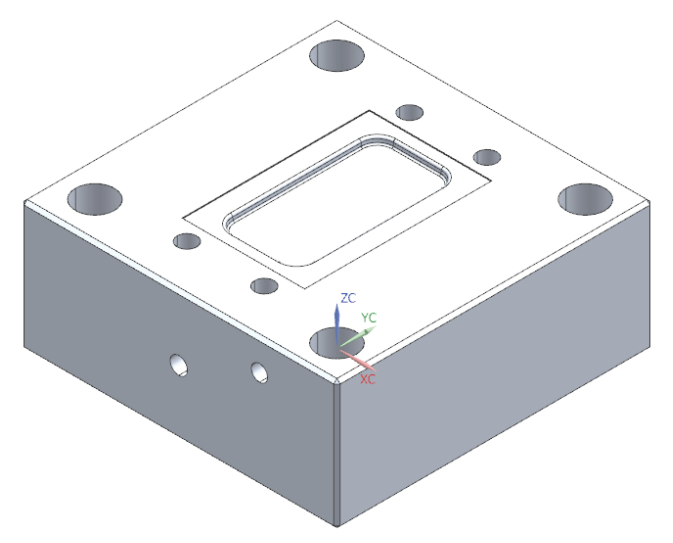

Şekil 2. Kalıbın katı modeli

Plastik enjeksiyon kalıplama yöntemi ile şekillendirmede enjeksiyon makinesinde ergiyen polimer, yüksek basınç kazandırılarak kalıba gönderilir. Tek taraflı kalıp üzerinde bulunan sac plaka ergiyen yüksek basınçlı polimer tarafından kalıp boşluğunun şeklini almaya zorlanır. Şekillendirme işleminin tamamlanmasının ardından sac parça ile katılaşan polimer malzeme birbirinden ayrılarak istenilen hassas, dar toleransa sahip, yüzeyleri düzgün sac parçalar imal edilmiş olur (Şekil 4). Çalışmada polimerin ergitilmesini ve kalıba yüksek basınçla gönderilmesini sağlayan 40 tonluk plastik enjeksiyon makinesi kullanılmıştır.

\subsection{Proses Parametreleri ve Deneysel Tasarim}

Plastik enjeksiyonuyla sac metal şekillendirme yöntemine ait daha önceki literatür çalışmaları incelendiğinde ergiyik polimer malzemesinin kalıba giriş sıcaklığının, enjeksiyon makinesinin uygulamış olduğu basınç ve proses hızının şekillendirilebilirliği, kalınlık ve malzeme iç yapı değişimlerini oldukça etkilediği görülmektedir [3]. Deneysel çalışmalarda bu nedenle kontrol faktörleri olarak; enjeksiyon basıncı, ergiyik polimer sıcaklığı ve enjeksiyon hızı seçilmiştir. Bu faktörlere ait seviyeler Tablo 4 ' te gösterilmiştir. Deneysel tasarım olarak Taguchi metodu kullanılarak daha az sayıda deney sonucunda optimum proses parametrelerinin belirlenmesi sağlanmıştır. Çalışmada $\mathrm{L}_{9}$ ortogonal matrisi esas alınarak deneysel çalışmalar gerçekleştirilmiştir.

Tablo 4' te görüldüğü gibi her kontrol faktörüne ait üçer seviye bulunmaktadır. Enjeksiyon basıncı olarak 40, 60 ve $80 \mathrm{MPa}$, ergiyik sıcaklığı olarak 200,220 ve $240^{\circ} \mathrm{C}$ ve enjeksiyon hızı olarak ise 30, 32 ve 34 (\%) değerleri deneysel çalışmalarda kullanılmıştır.
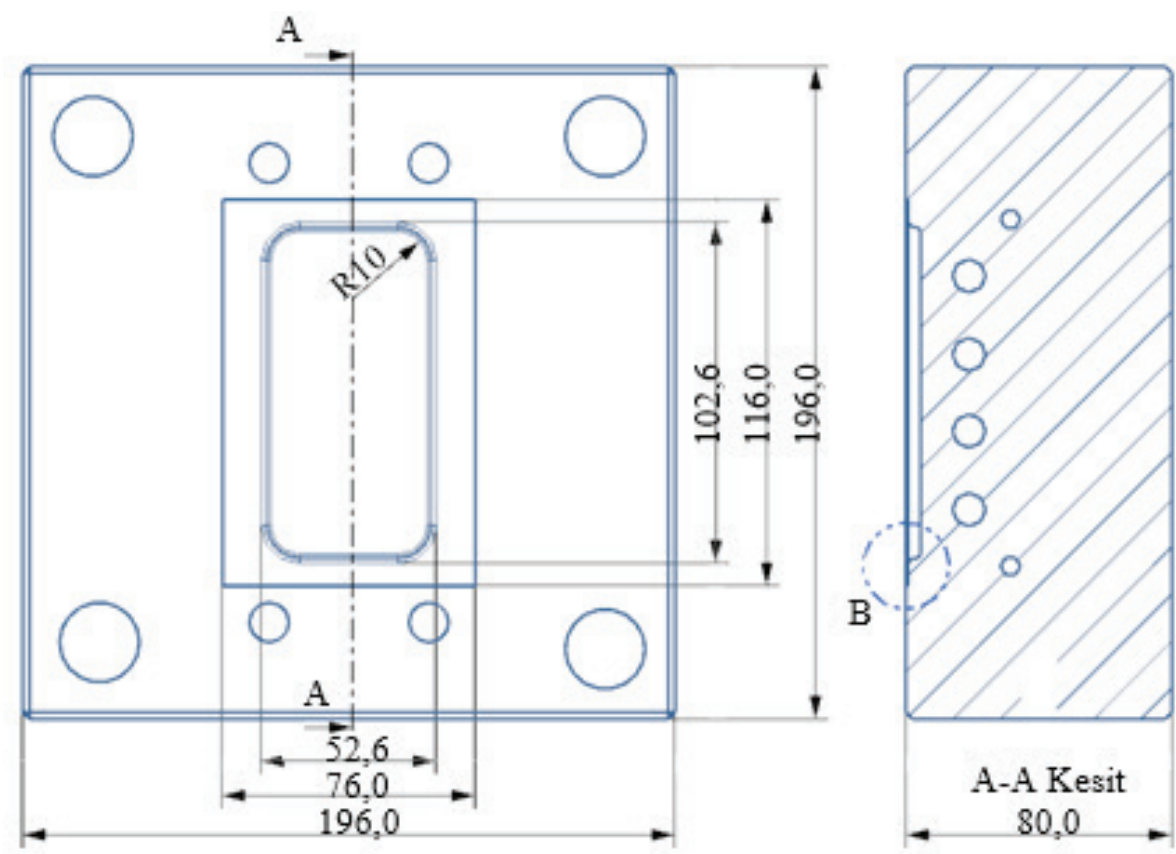

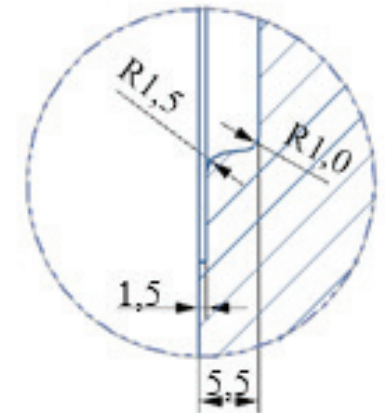

Detay B

$2: 1$

Şekil 3. Kalıbın boyutları (mm) 


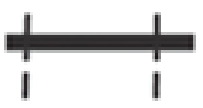

Sac levha
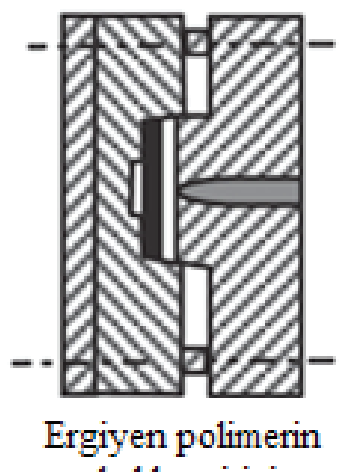

kalıba girişi



\section{Ergiyen polimerin} sac levhayı şekillendirilmesi

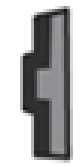

Son mamül

Şekil 4. Plastik enjeksiyon kalıplama ile şekillendirme

Tablo 4. Kontrol faktörleri ve seviyeleri

\begin{tabular}{lccccc}
\hline $\begin{array}{l}\text { Kontrol } \\
\text { Faktörleri }\end{array}$ & \multirow{2}{*}{ Sembol } & \multicolumn{3}{c}{ Seviyeler } & \multirow{2}{*}{ Sirim } \\
& & Seviye 1 & Seviye 2 & Seviye 3 & \\
\hline Enjeksiyon Basınc1 & $\mathrm{A}$ & 40 & 60 & 80 & $\mathrm{MPa}$ \\
Ergiyik Sıcaklığı & $\mathrm{B}$ & 200 & 220 & 240 & ${ }^{\circ} \mathrm{C}$ \\
Enjeksiyon Hızı & $\mathrm{C}$ & 30 & 32 & 34 & $(\%)$ \\
\hline
\end{tabular}

Şekillendirme sonrası imal edilen parçaların kalınlık değerleri frezeleme yöntemiyle dört eşit parçaya bölünerek parçanın iki kesiti boyunca ölçülmüştür: profil A, uzun kesit (A-A) ve profil B, kısa kesit (B-B), (Şekil 5). Ölçme işlemleri optik mikroskop kullanılarak \% 0,01 hassasiyetinde gerçekleştirilmiştir. Ölçüm sonuçlarının ortalamaları alınarak \% incelme değişimleri hesaplanmıştır (Şekil 6).

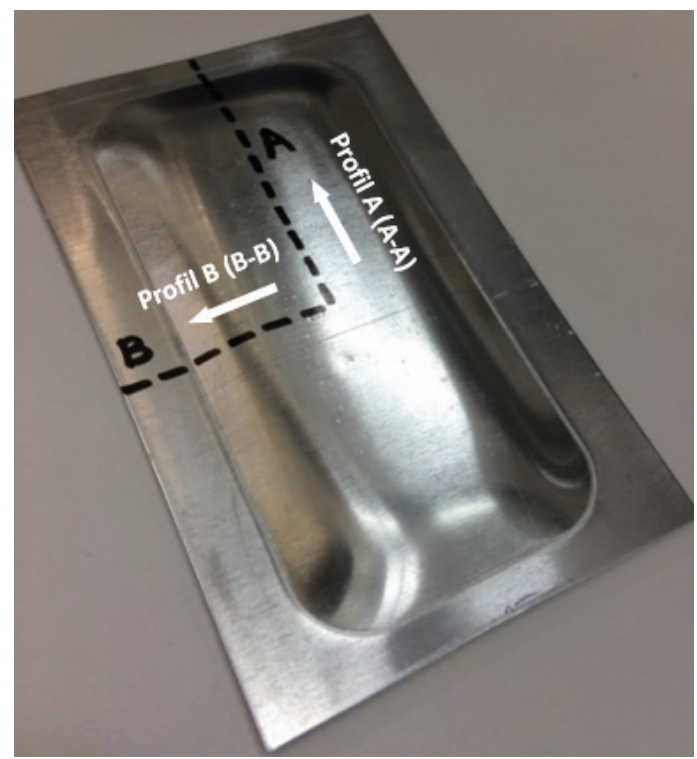

Şekil 5. Parça üzerindeki A-A ve B-B kesitleri

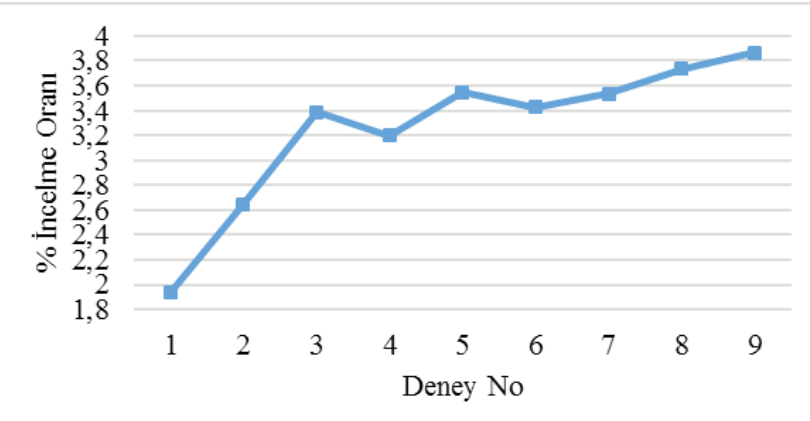

Şekil 6. 1,5 mm kalınlığına sahip alüminyum plakaların A-A ve B-B kesitleri boyunca meydana gelen \% incelme değişimleri

Alüminyum sac metal malzemesinin şekillendirilmesi sonucunda parçanın formunda yırtılma veya tolerans sınırları içerisinde aşırı incelme olmaması kaydıyla sac kalınlığına bağlı olarak maksimum şekillendirmeyi elde etmek amaciyla meydana gelen incelme miktarının en fazla olması istenmektedir. 1,5 mm sac kalınlığındaki plakalar ile gerçekleştirilen deneyler ve ölçümler neticesinde parça formunda herhangi bir yırtılma yada aşırı incelme durumuyla karşılaşılmamasından dolayı deneysel tasarımda yer alan sinyal/gürültü $(\mathrm{S} / \mathrm{N})$ oranının hesaplanmasında 'Daha büyük daha iyi" ifadesini temsil eden 1 nolu denklem esas alınmıştır. Bu denklemde n deney sayısını, $y_{\mathrm{i}}$ ' de elde edilen i. veriyi ifade etmektedir [12].

$$
\mathrm{S} / \mathrm{N}=-10 \cdot \log \left(\frac{1}{\mathrm{n}} \sum_{\mathrm{i}=1}^{\mathrm{n}} 1 / \mathrm{y}_{\mathrm{i}}^{2}\right)
$$

"En büyük en iyidir" yaklaşımına göre hesaplanmış $\mathrm{S} / \mathrm{N}$ oranlarına ait değerler Tablo 5' te sunulmuştur. Deneysel sonuçlar neticesince ölçülen incelme değerlerinin yorumlanması ile $\mathrm{S} / \mathrm{N}$ oranlarına bağlı olarak optimum proses parametreleri elde edilmiştir. 
Tablo 5. Çalışmada kullanılan L9 ortogonal dizisi, faktörler, incelme (\%) ölçüm sonuçları ve S/N oranları

\begin{tabular}{|c|c|c|c|c|c|c|c|c|c|}
\hline \multirow[b]{2}{*}{ Deney No } & \multicolumn{3}{|c|}{ Semboller } & \multicolumn{3}{|c|}{ Kontrol Faktörleri } & \multirow{2}{*}{$\begin{array}{c}\text { Son Kalınlık } \\
\text { Ortalaması [mm] }\end{array}$} & \multirow{2}{*}{$\begin{array}{c}\% \\
\text { İncelme }\end{array}$} & \multirow[b]{2}{*}{$\mathrm{S} / \mathrm{N}$} \\
\hline & A & B & $\mathrm{C}$ & $\begin{array}{l}\text { Basınç } \\
\text { [MPa] }\end{array}$ & $\begin{array}{c}\text { Sicaklık } \\
{\left[{ }^{0} \mathrm{C}\right]}\end{array}$ & $\begin{array}{l}\mathrm{Hiz} \\
{[\%]}\end{array}$ & & & \\
\hline 1 & 1 & 1 & 1 & 40 & 200 & 30 & 1,4710 & 1,933 & 5,7246 \\
\hline 2 & 1 & 2 & 2 & 40 & 220 & 32 & 1,4603 & 2,647 & 8,4551 \\
\hline 3 & 1 & 3 & 3 & 40 & 240 & 34 & 1,4492 & 3,387 & 10,5963 \\
\hline 4 & 2 & 1 & 2 & 60 & 200 & 32 & 1,4520 & 3,200 & 10,1030 \\
\hline 5 & 2 & 2 & 3 & 60 & 220 & 34 & 1,4468 & 3,547 & 10,9972 \\
\hline 6 & 2 & 3 & 1 & 60 & 240 & 30 & 1,4486 & 3,427 & 10,6983 \\
\hline 7 & 3 & 1 & 3 & 80 & 200 & 34 & 1,4470 & 3,533 & 10,9629 \\
\hline 8 & 3 & 2 & 1 & 80 & 220 & 30 & 1,4440 & 3,733 & 11,4412 \\
\hline 9 & 3 & 3 & 2 & 80 & 240 & 32 & 1,4420 & 3,867 & 11,7475 \\
\hline
\end{tabular}

\section{DENEYSEL SONUÇLAR VE TARTIŞMA}

\subsection{Taguchi Metodu Değerlendirmeleri}

Al-1050.O malzemesinin farklı proses parametreleri kullanılarak plastik enjeksiyonuyla şekillendirilmesi sonucu ölçülen incelme sonuçları Minitab 17 programı kullanılarak analiz edilmiştir. Kontrol faktörlerinin incelme üzerindeki etkilerini belirleyebilmek amacıyla $\mathrm{S} / \mathrm{N}$ yanıt tablosu oluşturulmuştur (Tablo 6). Her faktörün farklı seviyelerinden elde edilen maksimum ve minimum ortalama gürültü oranları arasındaki farkların daha fazla ya da daha az olması faktörlerin incelme üzerindeki etkinliği hakkında bilgi vermektedir. Farkların işaretine bakılmaksızın seviyeleri arasında büyük farka sahip olan kontrol faktörünün sonuç üzerinde daha etkili olduğu göz önüne alındığında Tablo 6' ya göre incelme üzerinde en etkili parametrelerin sırasıyla enjeksiyon basıncı (A), ergiyik sıcaklığı (B) ve enjeksiyon hızı (C) olduğu görülmektedir.

Tablo 6. (S/N) ortalamaları için yanıt tablosu

\begin{tabular}{cllccc}
\hline \multirow{2}{*}{ Semboller } & Kontrol & \multicolumn{4}{c}{ S/N Ortalamaları } \\
& Faktörleri & Seviye 1 & Seviye 2 & Seviye 3 & Max. - Min. \\
\hline A & Enj. Basınc1 & 8,25867 & 10,5995 & 11,3838 & 3,12513 \\
B & Erg. Sıcaklığ1 & 8,93017 & 10,2978 & 11,014 & 2,08383 \\
C & Enj. Hızı & 9,28803 & 10,1018 & 10,8521 & 1,56407 \\
\hline
\end{tabular}

$\sum(\mathrm{S} / \mathrm{N}) / 9=\mathrm{S} / \mathrm{N}$ ortalamalarının ortalaması 10,0806 olarak bulunmuştur. Elde edilen $\mathrm{S} / \mathrm{N}$ ortalamaları grafik olarak Şekil 7' de verilmiştir.

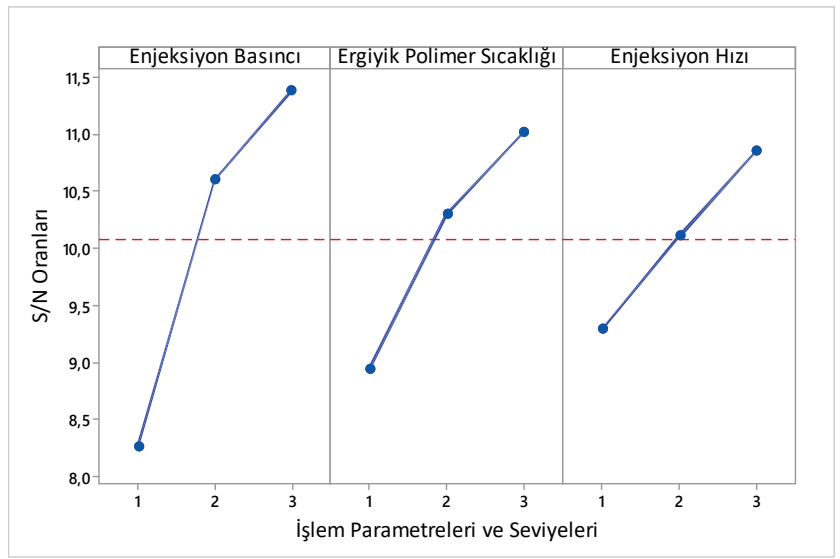

Şekil 7. \% incelme oranları için ortalama S/N grafiği (Daha büyük daha iyi)

Şekil 7' de kontrol faktörleri ve seviyelerine ait S/N oranları görülmektedir. Şekillendirme sonrasında 1,5 mm lik alüminyum plakalar için parçada meydana gelen incelme miktarının maksimum olmasının istenmesinden dolayı en büyük en iyidir kalite karakteristiğine göre yapılan optimizasyona göre, incelme miktarının en büyük olduğu seviyeler enjeksiyon basıncında $80 \mathrm{Mpa}$, ergiyik polimer sıcaklığında 240 ${ }^{\circ} \mathrm{C}$ ve enjeksiyon hızında $34 \%$ olmuştur. Buna göre maksimum incelmeyi sağlayan şekillendirme parametreleri "A3B3-C3" olarak belirlenmiştir. Yapılan deneysel çalışmada incelme değerlerinin optimal sonuçları elde edilmiştir. İncelme için optimum sonuca mevcut deneylerden ulaşılamamıştır. Bu nedenle ilave bir doğrulama deneyine ihtiyaç duyulmuştur. 
Plastik enjeksiyon kalıplama yöntemi ile şekillendirilmiş parçaların kalınlık değişimlerini etkileyen kontrol faktörlerinin sonuç üzerindeki \% katkı oranlarını belirleyebilmek amacıyla Varyans Analizi (ANOVA) kullanılmıştır. Her bir kontrol faktörünün incelme üzerindeki \% katk1 oranları Minitab 17 programından faydalanılarak $\% 95$ güvenilirlik seviyesinde hesaplanmıştır. Tablo 7' de her kontrol faktörüne ait \% katkı oranları verilmiştir. Buna göre incelme üzerinde en etkili parametrelerin sırasıyla; Enjeksiyon Basıncı: A $(59,84 \%)$, Ergiyik Sicaklığı: B $(23,46 \%)$ ve Enjeksiyon Hızı: C (10,75\%) olduğu gözlemlenmiştir. Enjeksiyon basıncı ve ergiyik sıcaklığının artmasıyla diğer literatür çalışmalarında olduğu gibi incelmenin arttığı ve basıncın şekillendirme üzerinde en etkili proses parametresi olduğu görülmüştür [3].

ANOVA sonuçları incelendiğinde Taguchi metoduyla elde edilen sonuçlarla paralellik gösterdiği görülmektedir. Her iki analizde de incelme üzerinde en fazla etkiye sahip parametre olarak enjeksiyon basincı ve en az etkiye sahip parametre olarak ise enjeksiyon hızı bulunmuştur.

\subsection{Regresyon Analizi ve Cevap Yüzey Metodu İle Tahminsel Denklemlerin Elde Edilmesi}

Al-1050.O malzemesinin plastik enjeksiyon yöntemiyle şekillendirilmesi sonucu parçalarda meydana gelen incelme miktarlarının tahmini için regresyon analizi ve cevap-yüzey metodu kullanılarak birinci ve ikinci dereceden tahminsel denklemler geliştirilmiştir. Lineer regresyon analizi ile elde edilen tahminsel denklemin korelasyon katsayıs $\mathrm{R}^{2}=$ 0,907 olarak hesaplanmıştır (Denklem 2). Denklemin oluşturulmasında kullanılan katsayılar Tablo 8' de gösterilmiştir. Korelasyon katsayısının yüksek olması elde edilen denklemin \% 90,7 doğruluğunda ve oldukça güvenilir olduğunun bir göstergesidir. Bu denklemin kullanılmasıyla 1,5 mm kalınlığındaki plakalar için mevcut deneylerden ulaşılamayan optimum A3-B3-C3 (80MPa- $\left.240^{\circ} \mathrm{C}-34 \%\right)$ seviyelerine ait tahminsel kalınlık değeri 1,4350 mm olarak hesaplanmıştır. Aynı parametrelerle gerçekleştirilen doğrulama deneyi sonucundaki kalınlık değeri ise $1,4395 \mathrm{~mm}$ olarak ölçülmüştür (Şekil 8).

Kalınlık $(\mathrm{mm})=1,5853-0,000396 \cdot \mathrm{A}-0,000252 \cdot \mathrm{B}-0,001717 \cdot \mathrm{C}$

Tablo 8. Regresyon analizine ait katsayılar

\begin{tabular}{ccccc}
\hline Notasyonlar & Katsayılar & SE Katsayılar & T-Değeri & P-Değeri \\
\hline Sabit & 1,5853 & 0,0280 & 56,56 & 0,000 \\
A & $-0,000396$ & 0,000071 & $-5,55$ & 0,003 \\
B & $-0,000252$ & 0,000071 & $-3,53$ & 0,017 \\
C & $-0,001717$ & 0,000713 & $-2,41$ & 0,061 \\
\hline
\end{tabular}

Cevap yüzey metodu ile elde edilen ikinci dereceden tahminsel denklem kullanılarak Taguchi deneysel tasar1mında yer alan belirli parametre değerlerine bağlı kalmaksızın kontrol faktörlerine ait istenilen ara değerler denklemde yerine yazılarak gerçeğe en yakın kalınlık değerleri tahmin edilebilmektedir (Denklem 3). Bu denklemde kontrol faktörlerinin birbirleriyle etkileşimleri de dikkate alınmaktadır.

Kalınlık $(\mathrm{mm})=1,814-0,004899 \cdot \mathrm{A}+0,000211 \cdot \mathrm{B}-0,01181 \cdot \mathrm{C}+0,000008 \cdot \mathrm{A}^{2}$.

$0,000001 \cdot B^{2}+0,000079 \cdot C^{2}+0,000003 \cdot A \cdot B+0,000089 \cdot A . C$

Değişen enjeksiyon basıncı ve ergiyik polimer sıcaklığının kalınlık üzerindeki etkilerine ait cevap yüzey metoduyla oluşturulan yüzey grafiği Şekil 9' da gösterilmiştir.

Tablo 7. \% İncelme oranları için varyans analizi

\begin{tabular}{lcccccc}
\hline Notasyonlar & Serbestlik Dereceleri & Kareler Toplam1 & Kareler Ortalamas1 & F Oran1 & P Değeri & Katk1 Oran1 (\%) \\
\hline A & 2 & 0,000395 & 0,000198 & 10,38 & 0,088 & 59,84 \\
B & 2 & 0,000155 & 0,000078 & 4,07 & 0,197 & 23,46 \\
C & 2 & 0,000071 & 0,000035 & 1,86 & 0,349 & 10,75 \\
Hata (e) & 2 & 0,000038 & 0,000019 & - & - & 5,75 \\
Toplam & 8 & 0,000660 & - & - & - & 100 \\
\hline
\end{tabular}




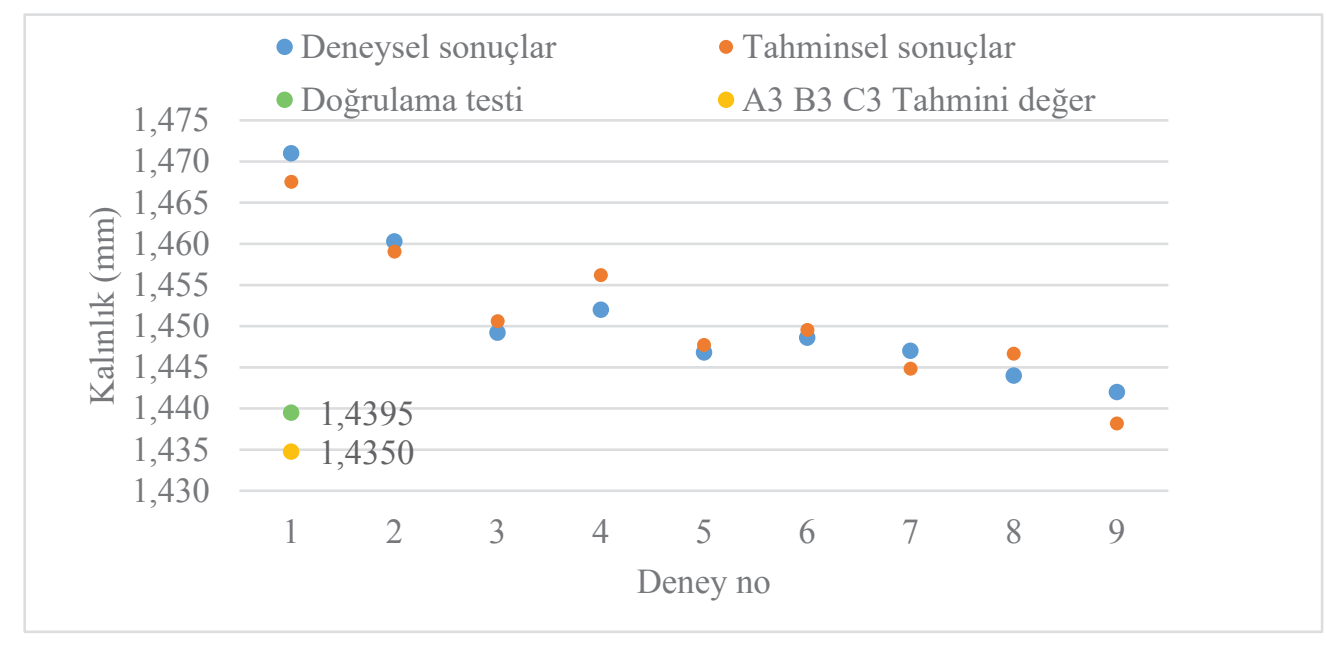

Şekil 8. 1,5 mm kalınlığında alüminyum saclar için deneysel ve tahminsel kalınlık değerleri

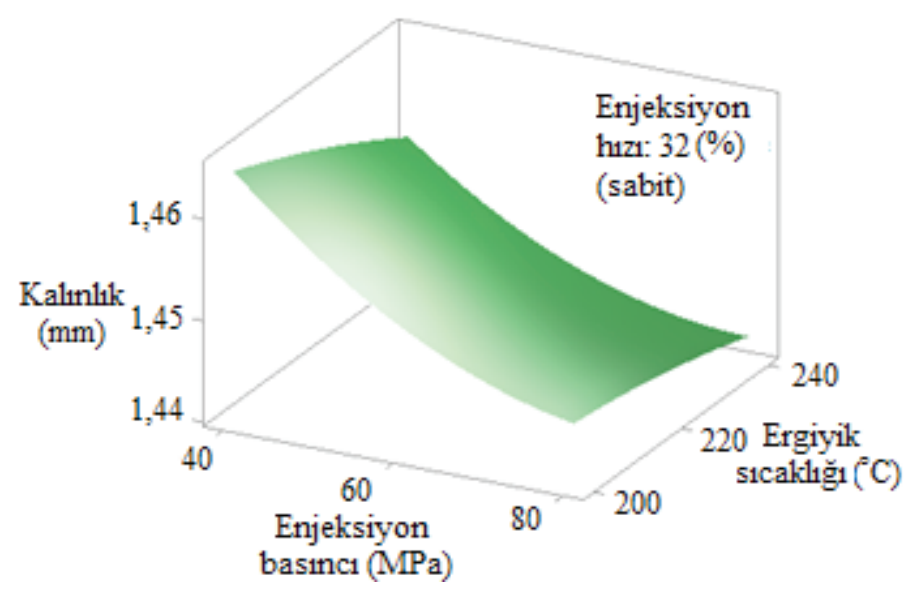

Şekil 9. Enjeksiyon basınc1 - Ergiyik polimer sıcaklığı - Sac metal kalınlık yüzey grafiği

Grafik incelendiğinde Taguchi ve ANOVA da olduğu gibi enjeksiyon basıncının incelme üzerinde diğer parametrelere kıyasla daha etkili olduğu anlaşılmaktadır.

Şekillendirme öncesi malzemeye uygulanan ön 1sıtma işleminin parçalar üzerindeki etkisini incelemek ve daha iyi sonuçlar elde edebilmek amaciyla optimum incelme sonuçlarına ulaştı̆ıımız 3-3-3 (80 MPa, $240{ }^{\circ} \mathrm{C}, 34 \%$ ) ve en az incelmenin görüldüğü 1-1-1 (40 MPa, $200{ }^{\circ} \mathrm{C}, 30$ \%) seviyeleri dikkate alınarak ek deneysel çalışmalar gerçekleştirilmiş̧ir. Şartlandırıcı yardımıyla kalıp ısıtılarak sac plakaların yüzey sıcaklıklarının $60^{\circ} \mathrm{C}$ ' ye ulaşması sağlanmıştır. Ön 1sıtma işlemi sonrası yapılan şekillendirme neticesinde 3-3-3 seviyeleri için ölçülen ortalama kalınlık değeri 1,4287 mm, 1-1-1 seviyeleri için ölçülen ortalama kalınlık değeri ise 1,4390 mm olmuştur. Elde edilen sonuçlardan ön 1sıtma işleminin şekillendirilebilirliği önemli oranda arttırdığı görülmektedir. Şöyle ki minimum incelmenin gerçekleştiği 1-1-1 kombinasyonu için uygulanan ön 1sıtma işlemi sayesinde daha yüksek basınç ve ergiyik sıcaklığında ulaşabileceğimiz yüksek şekillendirilebilirliğe çok daha düşük basınç ve sıcaklık değerlerinde ulaşılmıştır. Dolayısıyla, plastik enjeksiyon yöntemi ile sac metalin şekillendirilmesinde ön 1sıtma uygulanması ile çok daha düşük basınç değerleri uygulanarak istenilen incelme oranları elde edilmiştir. $\mathrm{Bu}$ da, literatürde belirtildiğinin aksine plastik enjeksiyonda sac şekillendirme için yüksek basınç gereksinimini ortadan kaldırmaktadır.

\section{SONUÇLAR}

Yapılan bu çalışmada otomotiv ve havacılık sektöründe oldukça sık kullanılan alüminyum sac metal malzemesinin yeni bir yöntem olan plastik enjeksiyon kalıplama ile şekillendirilmesinde proses parametrelerinin şekillendirilebilirlik üzerine etkileri araştırılmıştır. Al-1050.O malzemesinin şekillendirilmesinde, ergiyik sıcaklı̆̆ı, enjeksiyon basıncı ve hızı kontrol faktörlerinin optimal seviyelerini belirlemek amacıyla yapılan bu çalışmada kontrol faktörlerinin farklı seviyelerinde incelme oranları \%1,933 - \%3,867 aralığında bulunmuştur. İncelme üzerinde en etkili parametreler sırasıyla; Enjeksiyon Basıncı: A (59,84\%), Ergiyik Sicaklığı: B $(23,46 \%)$ ve Enjeksiyon Hızı: C (10,75\%) olduğu gözlemlenmiştir. Taguchi deneysel tasarımında; tüm kontrol 
faktörlerinin üçüncü seviyeleri $\left(\mathrm{A}=80 \mathrm{MPa}, \mathrm{B}=240^{\circ} \mathrm{C}\right.$, $\mathrm{C}=34 \%$ ) en yüksek şekillendirilebilirliği sağlayan optimum seviyeler olarak belirlenmiştir. Ergiyik sıcaklı̆̆ı, enjeksiyon basıncı ve hızının artmasıyla şekillendirilebilirlik artmıştır. Geliştirilen tahminsel denklemin korelasyon katsayısı $\mathrm{R}^{2}=$ 0,907 olarak hesaplanmıştır. Plastik enjeksiyonla sac şekillendirme yönteminde ön 1sıtma işleminin şekillendirilebilirlik üzerinde oldukça etkili olduğu görülmüştür. Düşük enjeksiyon basıncı değerlerinde dahi ön 1sıtma uygulanmış sac metallerin istenilen performansta şekillendirilebildiği tespit edilmiştir.

\section{KAYNAKLAR}

[1] Moralar, A. (2015). İnce sac levhaların yüksek basınç altında (hydroforming) şekillendirilmesi. Electronic Journal of Vocational Colleges, Cilt 5, Say1 4.

[2] Van Der Aa, H., Verdier, A. ve De Wolf, H. (2003). Method and device for producing a composite product and composite product produced therewith. World Patent WO 03/057446 Al.

[3] Koç, M., Ağçayazı, A. ve Carsley, J. (2011). An experimental study on robustness and process capability of the warm hydroforming process. Journal of Manufacturing Science and Engineering, 133, 021008-1.

[4] Lucchetta, G. ve Baesso, R. (2006). Polymer injection forming (PIF) of thin-walled sheet metal parts-preliminary experimental results. 10th Esaform Conference on Material Forming, at Zaragoza; Spain, April, 907, 1046-1051.

[5] Bariani, P.F., Bruschi, S., Ghiotti, A. ve Lucchetta, G. (2007). An approach to modelling the forming process of sheet metal-polymer composites. Annals of the CIRP, 56(1).

[6] Behrens, B.A., Bouguecha, A. ve Götze T. (2010). Consideration of fundamental influence parameters for the simulation of sheet-metal forming processes by means of plastic melt pressure. Mat.-wiss. u.Werkstofftech, 41(10).

[7] Prof. Dr.-Ing. Dr.-Ing E.h. Michaeli. W. ve Maesing. R. (2010). Injection moulding and metal forming in one process step. 25th International Plastics Technology Colloquium of the Institute of Plastics Processing (IKV), at RWTH Aachen University, Germany, March.

[8] Chen, M., Zhang, X., Lei, Q. ve Fu, J. (2002). Finite element analysis of forming of sheet metal blank in manufacturing metal/polymer macro-composite components via injection moulding. International Journal of Machine Tools \& Manufacture, 42, 375-383.

[9] Altan, M., Bayraktar, M. ve Yavuz, B. (2016). Manufacturing polymer/metal macro composite structure for vibration damping. International Journal of Advanced Manufacturing Technologies, 86, 2119-2126.

[10] Karaağaç, İ. ve Özdemir, A. (2009). Sıvı basıncı ile sac şekillendirme (SBŞ) yönteminin derin çekilebilirlik üzerine etkilerinin incelenmesi. 5. Uluslararası İleri Teknolojiler Sempozyumu (Iats'09), Karabük, Türkiye, 13-15 Mayıs.

[11] Landgrebe, D., Krausel, V., Rautenstrauch, A., Albert, A. ve Werteim, R. 2016. Energy-efficiency in a hybrid process of sheet metal forming and polymer injection moulding. Procedia CIRP 40, 109-114.

[12] Lee-Ing, T., Chao-Ton, S. ve Chung-Ho, W. (1997). The optimization of multi-response problems in the Taguchi method. International Journal of Quality\&Reliability Management, 14, 367-380. 